\title{
Design, Analysis and optimization of Hand Brake Lever
}

\author{
Chaitanya P. Deshpande*, Avinash Badadhe ${ }^{\#}$, Subim Khan ${ }^{\$}$ \\ *\#\$ Department of Mechanical Engineering, JSPM RSCOE SPPU, Pune, Maharashtra, India
}

(Received 1 February 2021; Accepted 7 April 2021)

https://doi.org/10.36224/ijes.140105

\begin{abstract}
In all automotive sector there is a linkage between brake mechanism and occupant known as a hand brake lever. Existing design is evaluated for optimization with use of composite material. CAD modeling of same will be done using CATIA V5 software. Finite element analysis approach is used to apply standard load on the part which is further investigated to perform Topology Optimization for material efficiency and reduction of cost. Existing design will then be machined as per topological optimization using Composite Material. Weight reduction of Brake lever will be done using Glass fiber epoxy composite material for optimized model. Static analysis of glass fiber hand brake lever will be performed using ANSYS19 software. The comparison of results between existing material and proposed composite material is done by using the techniques of Modal analysis and Static condition analysis of the part

Keywords: FEA, Topology optimization, Composite material, Fiberglass
\end{abstract}

\section{Introduction}

To stop a vehicle in an emergency condition on road or slope areas emergency brake or hand brake is used to keep vehicle in stationary order. In old vehicles it is observed that mechanism of lever is quite different than present era as it is observed that in past vehicle consist of a cable which is connected to brake at one location and the other end of cable is connected to driver hand which acts as a pulling mechanism to apply emergency brake. In many autos the stopping slowing mechanism process works just on the back wheels, which have diminished footing while at the same time slowing down. The most well-known used process framework for a leaving brake is to keep a vehicle still when it is left. The stopping framework brake has a fastener or other locking system that will keep it connected with until physically discharged. Stopping brakes frequently comprise of a link associated with two-wheel brakes, which is then associated with a pulling system. In many vehicles, the leaving brake works just on the back wheels, which have diminished footing while at the same time slowing down. The instrument might be a a straight draw handle situated close to the controlling section or a foot-worked pedal situated with different pedals.

Hand brakes or parking brakes are used to continuously apply brakes to the vehicle so that it will not roll back to down-slope. When the lever is pulled a cable is pulled which is attached to the brakes. As the lever moves a cable attached to its end will actuates the drum brakes. As the drum brakes get actuated it will apply brakes to the wheel until and unless the pointer pressed which is used to again make the brake to come at its rest position. Design of Brake Lever includes while designing of bike brake lever material should be precisely selected along with cost and material properties must be studied in a proper way to implement it.

\section{Literature review}


M.R. Mansor et al. [1] In this article it presented automotive parking made up of kenaf fiber polymer composites along with inventive problem-solving theory to understand the effect on it and also analytic Hierarchy Process (AHP) methods. In this research five new concept designs for the kenaf fiber polymer composites automotive parking brake lever were developed using the integrated TRIZ-Morphological Chart-AHP method. The solution at conceptual design stage was made possible by using TRIZ method based on the TRIZ 40 inventive principles approach with are segmentation, local quality and composite materials and the idea generated were further refined into explicit structure highlights utilizing the morphological graph. The coordinated TRIZ-Morphological Chart-AHP strategy demonstrated ready to be applied connected at the hip in performing thought age, thought refinement, idea structure advancement and idea plan choice procedures and gives orderly just as all-encompassing simultaneous building approach in accomplishing the ideal arrangement particularly in creating calculated plan of kenaf fiber polymer composites car leaving brake switch segment.

J.L. Santolaya et al. [2] in this paper a front brake handle for large displacement motorcycles is designed. The three aspects have been studied namely operation, user adaptation and manufacturing process. The rider brakes bike by the joined activity of mechanical and pressure driven frameworks, which significantly increment the power performed by hand. The ergonomics of the system must consider various perspectives, which incorporate the general situation of the brake handle on the bike, the handlebar curvature and flow of the handlebar or the utilization of gloves by the pilot. It is concluded that the use of methodology takes into account three main aspects the effective operability of the mechanism, the adequate adaptation to the rider who will act on it and the viability of the development and manufacturing process. The analysis of all these aspects jointly has been essential to attain an optimized design. The final structure of the system and the shapes and measurements of their segments permit getting an adequate increase of the pilot power to stop totally the motorcycle. Consequently, the plan can fit appropriately to the gloved right hand of the pilot and to offer more noteworthy customizability and slowing down control than a traditional brake handle.

Amit B. Maske et al. [3] In this paper it presents without pulling or pushing the switch, the stopping brake won't work. Likewise, it is recommended that occasionally because of heedlessness or in crisis conditions, we people regularly neglect to apply stopping brakes. Once in a while if administration brake bombs leaving brakes are utilized as a crisis brake to stop the vehicle. This new stopping slowing mechanism likewise alluded to as brake by-wire, supplant traditional stopping brake hand switch with an electronic switch. This happens by supplanting traditional linkages with electric engine driven units. The slowing down power is produced straightforwardly by elite DC engines and rigging decrease by which stopping brake is applied. As more space accessible at the front side of the driver's lodge, we can present another seat or a kid seat as case in the littler vehicles. Slowing down activity will be initiated and deactivated uniquely by simply going ahead OFF switch Worm $\mathrm{n}$ worm gar goes about as a locking component for applying brakes. New planned stopping slowing mechanism has total programmed activity for simple drivability and security.

Mohd Razmi Ishak et al. [4], In this paper it presents the impact of the parking brake temperature decrease on the cinching power of the leaving slowing mechanism has not been very much tended to in spite of the way that it might bring about vehicle roll away. This paper builds up a one-dimensional (1D) model of driving trailing drum-type stopping brake model. This brake model is then confirmed with tests completed on a test seat that has been checked with the hand slowing mechanism in the vehicle. The outcomes from the examinations show a decent connection with the anticipated outcomes from the brake model. It is likewise discovered that the current stopping brake configuration fulfills the guideline prerequisites. Another finding is that the brake torque marginally increments as the drum temperature increments. At that point, a one-dimensional stopping brake model with thought of temperature impact is 
proposed. The outcome additionally shows that the torque produced by the stopping brake in the declining course is a lot higher than in the tough heading. This is because of the main trailing shoe type utilized in the drum brake system. It is seen that the drum brake torque isn't particularly influenced by temperature decrease. It is inferred that the vehicle won't roll away when the rubbing coefficient of the brake lining is above 0.2 and that the leaving brake can hold the vehicle fixed with five tenants inside it.

\section{Problem definition}

Hand brake levers are cantilever structure utilized for moving movement from inhabitant to slow down system. Existing structure should be examined for mass streamlining, reduce the stress hence forth diminishing the cost and material strength improvement. To investigate the component for use of composite material (GFC). To perform topology optimization for weight reduction of existing hand brake.

\section{Method of analysis}

Step 1: Initially research papers are studied to find out research gap for project then necessary parameters are studied in detail. After going through these papers, we learnt about parking hand brake.

Step2:- After deciding the components, the $3 \mathrm{D}$ Model and drafting will be done with the help of CAD software.

Step 3: - The Results for existing and proposed material (glass fiber composite) will be analyzed.

Step 4: - Topology optimization will be performed on the given component to give material efficiency and weight reduction.

Step 5: -The results are then lastly compared for both the cases and conclusion is drawn.
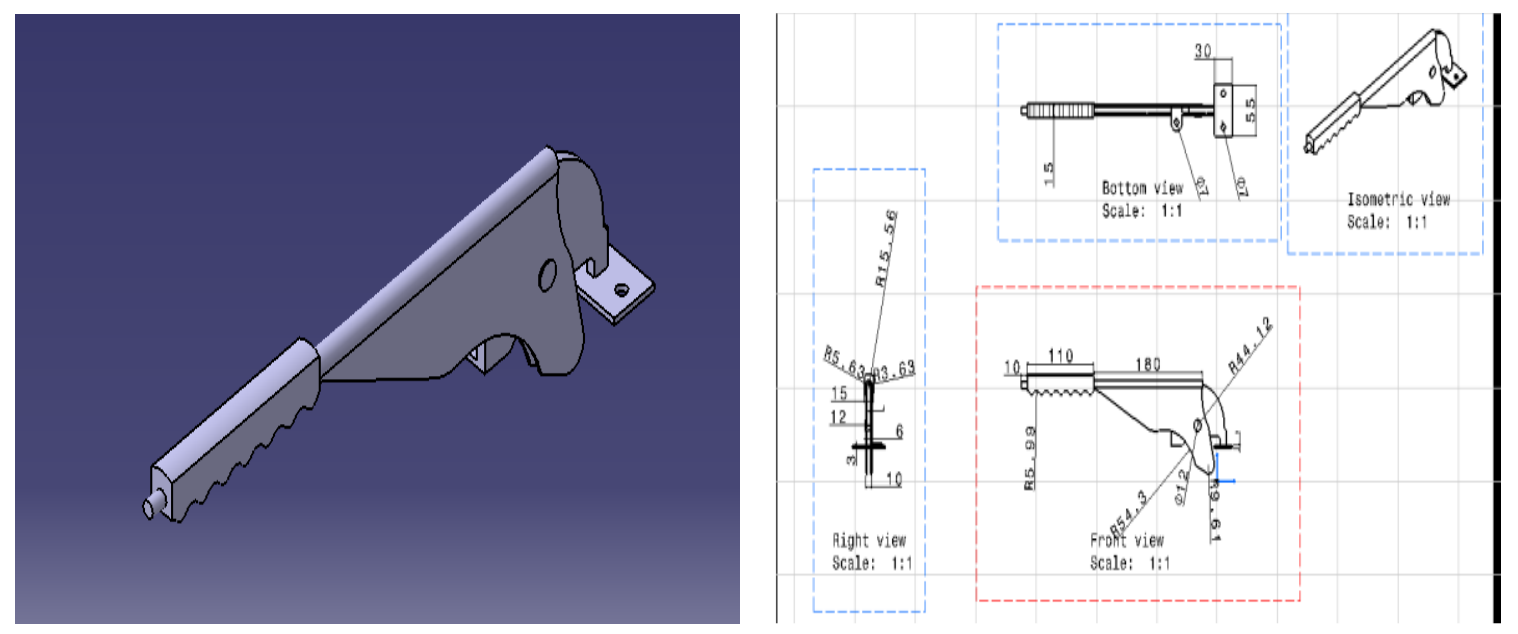

Figure 1: CAD model and Drawing of the component

\subsection{Modal Analysis}

In ANSYS the CAD models is imported and meshing is performed as similar to discretization process in FEA procedure in which it breaks whole components in small elements and nodes. So, in analysis boundary condition equations are solved at this elements and nodes. ANSYS Meshing is well suited and efficient for geometry based components. Mesh size along with fine tuning can be selected to capture the full geometry. Flow of mesh and its uniformity is important to get the better results by avoiding any stress concentrations. The material and properties are applied for solid geometry with structural steel. 


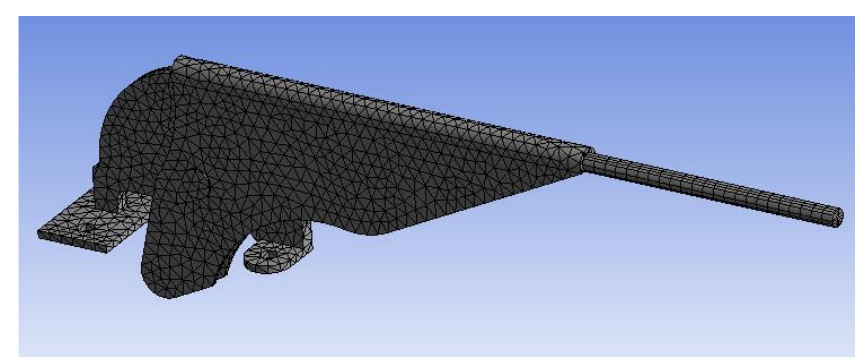

Figure 2: Meshing details in ansys

Modal Analysis is conducted on the given component. Fixed support is applied at base as per existing boundary condition. The stress and displacement from modal analysis are not actual therefore not accurate, the direction in which part vibrates and frequency are important. Modal analysis is done to get the mode shapes and frequency of the component. Which region would experience high stress can be deduced from mode shape along with stiffness of model in particular direction. Figure 4 and 5 shows the first mode of vibration and subsequent modes with frequency.

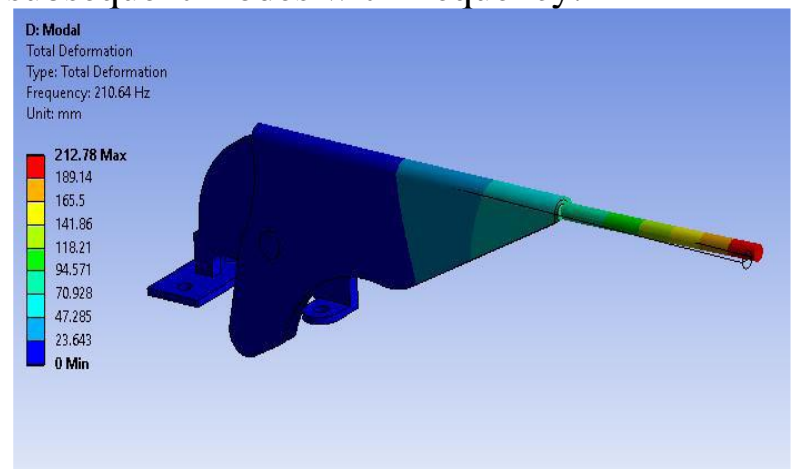

Figure 3: First mode of vibration

Tabular Data
\begin{tabular}{|l|l|l|l|}
\hline & Mode & $\sqrt{ }$ & Frequency $[\mathrm{Hz}]$ \\
\hline 1 & 1. & 210.64 \\
\hline 2 & 2. & 367.42 \\
\hline 3 & 3. & 467.67 \\
\hline 4 & 4. & 777.03 \\
\hline 5 & 5. & 1149.1 \\
\hline 6 & 6. & 1181.5 \\
\hline
\end{tabular}

Figure 4: Tabular data of mode shape frequency

\subsection{Static Analysis}

Boundary condition are applied as per calculation in present study fixed support is applied at base lifting force of $100 \mathrm{~N}$ force by hand on lever according to standard value for braking is applied at handle section indicated in red region.

After applying boundary conditions to the component and solving it for equivalent von-mises stress and total deformation results. We get the following results.

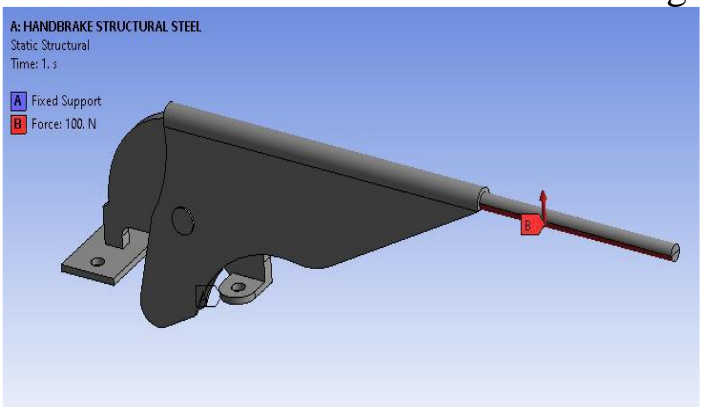

Figure 5: Loading conditions

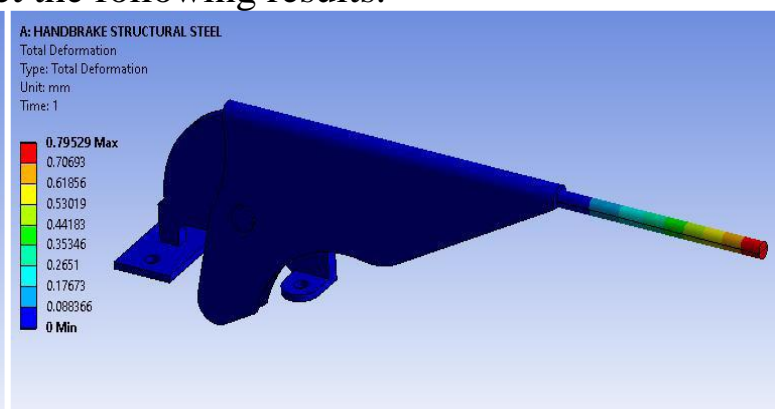

Figure 6: Displacement results for steel material 


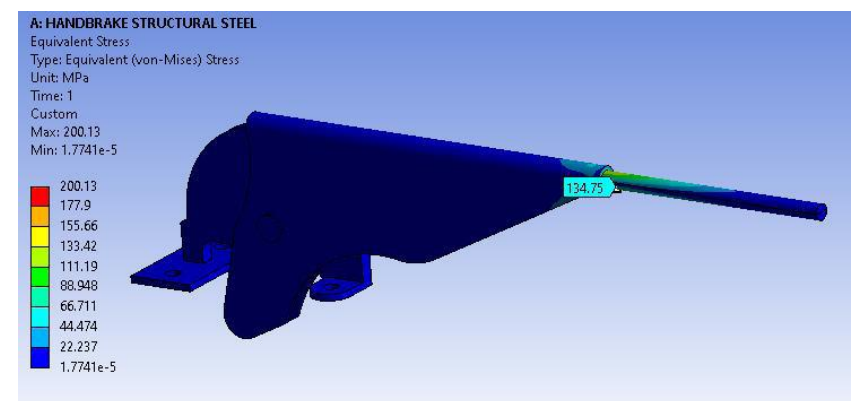

Figure 7: Equivalent stress results for steel

\subsection{Topology optimization}

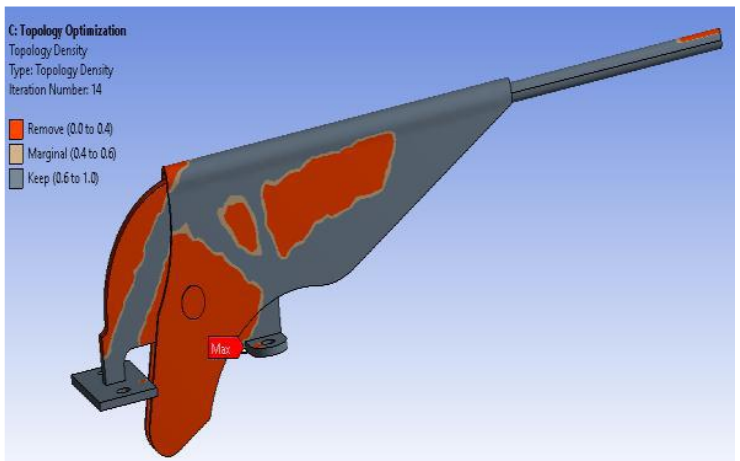

Figure 8: Topology optimization regions

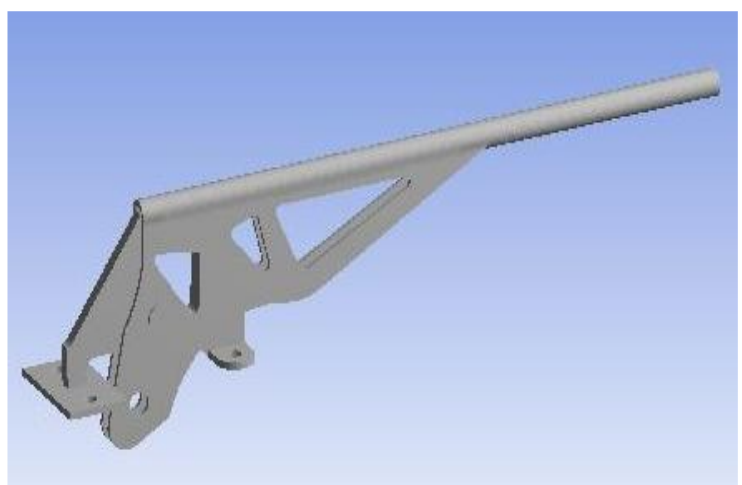

Figure 9: Modified part from Topology Optimization

For Topology optimization material is then changed to Glass fiber composite. Topology optimization is performed after static structural analysis with existing boundary condition to determine material removal area. After performing topology optimization red region indicates the material removal area from which material can be removed as per our need. The region is identified with topology optimization results and model is recreated in ansys giving smoother finish and drawing facets. The new design of model is created from that using standard sizes for dimensions of slots and fillets.

So, in our case original mass is $0.621 \mathrm{~kg}$ but removal of material is about to $0.35 \mathrm{~kg}$ as per software. But it depends on us to removal of material by proper design and reanalysis as per existing conditions to sustain boundary condition.

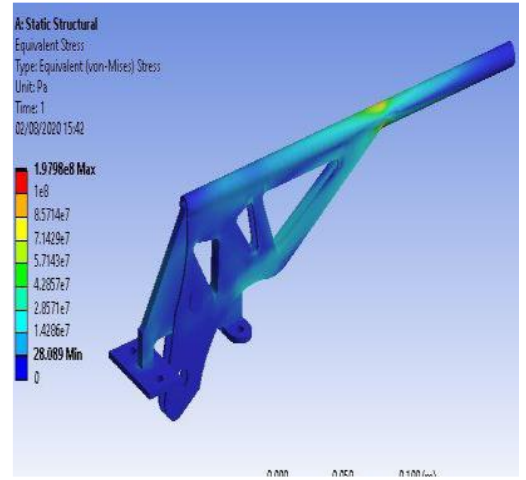

Figure 10: Modified part Equivalent stress analysis

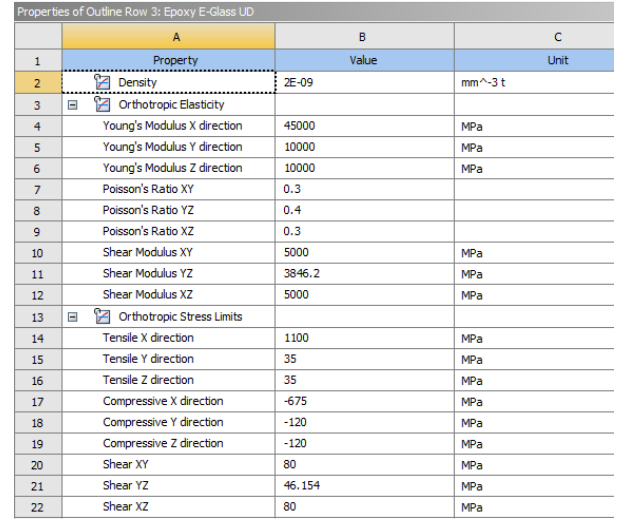

Figure 11: Fiberglass material properties 
Appropriate material regions and fillets are maintained so as to avoid stress concentration in areas. The results from static analysis of the modified part are shown which are well below the failure criteria. The stress value (197MPa) of modified design with Glass fiber composite as new material is lower than the value for existing material as show in fig. 8 and also safe from failure for the composite material for $50 \%$ of fiber composition (330Mpa). The deformation value is $2.5 \mathrm{~mm}$ slightly greater than previous case therefore acceptable.

\section{Results and discussion}

The modal analysis of component is done to get the dominant mode shapes. Static structural analysis of the existing and modified component after topology analysis is done and both the results are compared. The modified component of new design is found safe to use as stress value are below failure criteria. The Glass fiber composite component can be used for the given application. Also next we are going to testing $\&$ Inspection of the part.

Static structural analysis of hand brake with conventional material (structural steel) is performed to determine deformation and equivalent stress. It is observed that around maximum deformation is 0.79 $\mathrm{mm}$ and equivalent stress is $200.13 \mathrm{MPa}$. An optimized model is obtained from topology optimization technique in which it indicates material removal area. So, in our case original mass is $0.621 \mathrm{~kg}$ but removal of material is about to $0.35 \mathrm{~kg}$ as per software.

\section{Conclusion}

As per objective mentioned composite material of E glass epoxy is to be used to restructure the existing hand brake. It is observed under similar boundary conditions composite material have good results as stress have reduced to $197 \mathrm{MPa}$ compared to the tensile strength of the composite material with $50 \%$ fiber composition (300MPa). Composite strength increases with increase in fiber percentage, slight increase in deformation but not much high. So, it can be stated that using composite material compared to conventional not only improve strength but also provide material efficiency with decrease in weight of the component.

\section{References}

[1] Fargas Cabanillas, Josep Maria Olivé Delgado, Roger Sansalvadó Cabonés, Clara, Bike Brake Lever Design, Barcelona School of Industrial Engineering, ETSEIB

[2] Robin Larsson ,Methodology for Topology and Shape Optimization: Application to a Rear Lower Control Arm, Chalmers University of Technology, ISSN 1652-8557

[3] M.R. Mansor, S.M. Sapuan, E.S. Zainudin, A.A. Nuraini, A. Hambali. Conceptual design of kenaf fiber polymer composite automotive parking brake lever using integrated TRIZ-Morphological Chart-Analytic Hierarchy Process method, ELSEVIER, Materials and Design 54:473-482, August 2013

[4] J.L. Santolaya, J. Sevil, R. Miralbés., Design of a Hydraulic Front Brake Handle for Large Displacement Motorcycles,The Manufacturing Engineering Society International Conference, MESIC 2013, ELSEVIER

[5] Amit B. Maske,P.K Satav, Design \& Analysis of Parking Brake System of Car , International Journal of Innovative Research in Science, Engineering and Technology (An ISO 3297: 2007 Certified Organization) Vol. 5, Issue 7, July 2016

[6] Mohd Razmi Ishak , Abd Rahim Abu Bakar, Ali Belhocine b,, Jamaludin Mohd Taib , Wan Zaidi Wan Omar, Brake torque analysis of fully mechanical parking brake system: Theoretical and experimental approach, Measurement 94 (2016) 487-497, Elsevier 
[7] Pawan Kumar, Sanjay Gupta, Design Modification \& Shape Optimization of Automobile Brake Lever, IJSRD - International Journal for Scientific Research \& Development| Vol. 5, Issue 07, 2017 | ISSN (online): 23210613

[8] M.V. Aditya Nag, "Topology Optimization of Engine Mounting Bracket”, Hyperwork's Technical Conference, 2012 India.

[9] ttps://www.altair.com/topology-optimization/ 